\title{
Temporary Percutaneous Gastric Electrical Stimulation: Significant Progress in the Treatment of Drug-Refractory Vomiting and Nausea
}

\author{
Philippe Ducrotté Guillaume Gourcerol
}

Rouen University Hospital and EA 4311, Rouen, France

The relief of patients with chronic vomiting and/or nausea is a clinical challenge when symptoms are drugrefractory and have a significant impact on the nutritional status of the patient. A promising therapeutic approach in such cases is high-frequency (HF) gastric electrical stimulation (GES). The technique consists in delivering short (less than $1 \mathrm{~ms}$ ) and HF (approximately fivefold higher than the basal gastric pacemaker rate) electrical pulses via two electrodes implanted in the wall of the gastric antrum. In patients unresponsive to a pharmacological approach by any type of prokinetics (including erythromycin), several studies have demonstrated the efficacy of HF-GES with the improvement of nausea and/or vomiting, and also other gastroparetic symptoms, nutritional parameters, quality of life and glycemic control in the subgroup of diabetic patients with gastroparesis.

However, the technique is not always effective and predictive parameters for a therapeutic success remain to be precisely determined. If diabetic patients with gastroparesis appear to be good candidates for HF-GES, results are less convincing in some patients with idiopathic [1] or postsurgical gastroparesis [2]. Moreover, treatment by HF-GES is invasive with the need for a short stay in a surgical unit to implant the stimulator, while the cost of the device remains high. Therefore, careful selection of good candidates for this therapeutic option is important. A major step in the selection of good candidates for treatment of fecal incontinence by electrical stimulation of the sacral roots was to test the effect of temporary stimulation. This appeared to be a significant therapeutic progress [3]. In this issue of the journal, Andersson and colleagues, from Gothenburg, Sweden, report their experience with temporary percutaneous (TP) GES in 27 non-diabetic patients with intractable drug-refractory nausea and/or vomiting. With their technique, the implantation is guided by gastroscopy after transabdominal identification of the stomach position and the electrodes are inserted through the abdominal wall before being sewn into the gastric wall. To secure the electrode in the submucosa, the tip of the electrodes is T-shaped with a pair of flexible tines. The procedure seems simple, well tolerated and also safe, and no infection was reported despite a TP-GES of at least 2 weeks. The clinical impact of TP-GES is obvious as it allowed Andersson and colleagues to select $81 \%$ of the 27 possible candidates for definite implantation after increasing the intensity of stimulation from 5-7 to 8-10 $\mathrm{mA}$ in some patients. These results confirm those reported by Ayinala et al. [4] with orally or PEG-placed electrodes.

Another question to answer about HF-GES is whether patients other than those with diabetic, idiopathic or postsurgical gastroparesis may benefit from the tech-

\section{KARGER}

Fax +4161306 1234 E-Mail karger@karger.ch www.karger.com
(C) 2010 S. Karger AG, Base

0012-2823/11/0832-0001\$38.00/0

Accessible online at:

www.karger.com/dig
Philippe Ducrotté

Département d'Hépato-Gastroentérologie et de Nutrition, CHU de Rouen

1 rue de Germont, FR-76031 Rouen (France)

Tel. +33 2328867 07, Fax +3323515162311

E-Mail philippe.ducrotte@chu-rouen.fr 
nique. Indications for HF-GES were first limited to patients with objective gastroparesis. But, the lack of a relationship between the symptom relief and the acceleration of gastric emptying in most of the studies led to the consideration that underlying gastroparesis is not an absolute criterion to discuss HF-GES. We and others have demonstrated that HF-GES is also effective for the relief of vomiting and nausea in patients without delayed gastric emptying [5]. Now, another question to answer is whether patients with severe motility disturbances, particularly those due to chronic intestinal pseudo-obstruction, intestinal neuropathy, scleroderma or even Parkinson's disease, are possible candidates. Until now, these patients have been excluded from clinical trials, probably because of the low probability of improvement. This is the second important message of the article by Andersson et al. Some patients may benefit from the technique. For instance, in the experience of the Swedish group, 2 patients with chronic intestinal pseudo-obstruction were successfully implanted after successful TP-GES.

The article by Andersson and colleagues is important in that it demonstrates that TP-GES is promising for better selection of candidates for GES with a possible extension of the indications. This is a major step in the development of this treatment. The possibility for other centers to obtain these temporary electrodes is now urgently needed.

References

1 Maranki JL, Lytes V, Meilahn JE, Harbinson S, Friedenberg FK, Fisher RS, Parkman HP: Predictive factors for clinical improvement with Enterra gastric electrical stimulation treatment for refractory gastroparesis. Dig Dis Sci 2008;53:2072-2078.

2 Gourcerol G, Chaput U, Leblanc I, Gallas S, Michot F, Leroi AM, Ducrotte P: Gastric electrical stimulation in intractable nausea and vomiting: assessment of predictive factors of favorable outcomes. J Am Coll Surg 2009;209:215-221.

3 Jarrett ME, Dudding TC, Nicholls RJ, Vaizey CJ, Cohen CR, Kamm MA: Sacral nerve stimulation for fecal incontinence related to obstetric anal sphincter damage. Dis Colon Rectum 2008;51:531-537.
4 Ayinala S, Batista O, Goyal A, Al-Juburi A, Abidi N, Familoni B, Abell T: Temporary gastric electrical stimulation with orally or PEG-placed electrodes in patients with drug refractory gastroparesis. Gastrointest Endosc 2005;61:455-461.

5 Gourcerol G, Leblanc I, Leroi AM, Denis P, Ducrotté P: Gastric electrical stimulation in medically refractory nausea and vomiting. Eur J Gastroenterol Hepatol 2007;19:29-35. 